\title{
The Influence of Margin Trading and Short Selling on the Price Efficiency of China's Stock Market-Based on Portfolio Perspective
}

\author{
Linjie Huang \\ School of Economic, Jinan University, Guangzhou, China \\ Email: cecilia_jnu@126.com
}

How to cite this paper: Huang, L.J. (2019) The Influence of Margin Trading and Short Selling on the Price Efficiency of China's Stock Market-Based on Portfolio Perspective. American Journal of Industrial and Business Management, 9, 49-62.

https://doi.org/10.4236/ajibm.2019.91004

Received: December 7, 2018

Accepted: January 7, 2019

Published: January 10, 2019

Copyright $\odot 2019$ by author(s) and Scientific Research Publishing Inc. This work is licensed under the Creative Commons Attribution International License (CC BY 4.0).

http://creativecommons.org/licenses/by/4.0/

\begin{abstract}
In this paper, we use the natural experiment, the "false vaccine event" happening in Changsheng Life Biotechnology Co., Ltd. in the biological vaccine industry, to study whether the margin trading and short selling restriction will have an impact on the stock pricing. We built four different hedge portfolios based on the nature of whether the 22 stocks in the biological vaccine industry could be shorted, and the simulation of portfolio returns was shown three months after the "false vaccine event". The cumulative return of the portfolio reached a level of $10 \%-20 \%$. Furthermore, based on the adequacy of stock price information content and the timeliness of stock price response to information, this paper constructs an index to measure the pricing efficiency of individual stocks. Through regression analysis, we find that among 22 stocks in the biological vaccine industry, the pricing efficiency of stocks which are allowed to carry out margin trading and short selling business is significantly higher than that of which are not allowed to carry out margin trading and short selling business. Based on the difference of return characteristics and pricing efficiency index of hedge portfolio, this paper shows that margin trading and short selling system can help to correct the mispricing of individual stocks and improve the pricing efficiency of the market.
\end{abstract}

\section{Keywords}

Margin Trading and Short Selling, Short Selling Restriction, Price Efficiency, Hedge Portfolio

\section{Introduction}

Efficient market theory holds that in a stock market with a healthy legal system, good functions, high transparency, and full competition, all valuable informa- 
tion has been timely, accurately, and fully reflected in the stock price and their tendency, including the current and future value of the firms. It is impossible for investors to obtain abnormal profits above the market average by analyzing past prices or companies' basic information, unless there is market manipulation. However, the real stock market is not perfect. When there are a lot of financial frictions that affect the reflection of the real value of the stock price, the stock will be mispriced. Short selling restriction is a common financial friction in the stock market. The introduction of margin financing system in our stock market makes it possible to "buy long" and "short sell". It can reduce the financial friction of the market and it is helpful to improve the pricing efficiency of stock price in theory. However, some scholars believe that the lifting of the short selling restrictions will exacerbate the tendency when the stock market falls, leading to the misvalue of the stock price. Therefore, from an empirical point of view, it is of great significance to study the impact of the establishment of margin system on the pricing efficiency of China stock market.

In the theory of finance, the theoretical model of the influence of short selling restriction on stock price has been put forward very early. Miller (1977) established a model to point out that investors who are optimistic about the future will choose to buy and hold stocks under the background that investors has heterogeneous expectations and short selling restrictions exist while investors who are pessimistic about the future are unable to participate in the market because of the restrictions on short selling, so they can only choose to leave the market. The stock price cannot fully express the expectations of all market participants, resulting in the stock price deviating from the true value. The more severe the short selling restriction, the more overvalued the stock price, which mainly reflects the information of optimistic investors [1]. Duffie, D., Garleanu, and Pedersen (2002) believed that the increase of search cost and transaction cost will form an endogenous constraint on the short selling behavior of investors, which will have an impact on the efficiency of asset pricing [2]. Similarly, Aitken, M. J., Frino, Mccorry, and Swan (1998), Danielsen and Sorescu (2001) found that the introduction of the short selling mechanism can improve the speed of asset price to absorb negative information and thus improve the pricing efficiency [3] [4]. However, referring to Allen and Gale (1991), when analyzing the influence of short selling restriction on social welfare, it is found that the market can achieve complete competition and effective equilibrium under the condition of restricting short selling, but in the environment of unlimited short selling, complete competition and effective equilibrium cannot be realized [5]. Huang Feiming (2018) measures the abnormal volatility of stock price from frequency and amplitude, and finds that margin trading will increase the frequency of abnormal volatility and expand the range of abnormal fluctuation of stock price [6]. What's more, Brunnermeier and Pedersen (2005) found that the manipulation of short sellers can cause price overreaction to information and reduce the efficiency of asset pricing [7]. Based on the viewpoints above, this paper attempts to explore whether short-selling restrictions will have an impact on the pricing effi- 
ciency of stocks by constructing hedging portfolios with event driven.

In addition, considering that it may lack of sufficiency to analyze the effect of margin financing on stock pricing efficiency simply from the perspective of hedge portfolio income, this paper constructs the index of stock price volatility (PSF) and the index of stock price lag (PL) to measure pricing efficiency from two dimensions which are the content of price heterogeneity information and reaction speed of stock price to information and then analyzes the influence of margin financing system on pricing efficiency of individual stock. In summary, this paper will provide empirical evidence to demonstrate the impact of margin trading and short selling system on the efficiency of stock pricing from the two angles of hedge portfolio income and the significance of margin trading and short selling system variables.

The main contributions of this paper are as follows: on the one hand, considering that there are few papers in China to study the effect of margin financing on stock pricing efficiency through the perspective of hedge portfolio construction, this paper selects "false vaccine event" happened in Changsheng Life Biotechnology Co., Ltd. as an external event shock, defines the listed company in the biological vaccine industry as two groups according to the margin trading and short selling system: the short-selling group and the non-short-selling group, constructs the hedge portfolio by buying the stock portfolio that cannot be short and shorting the stock that is allowed to short, and examines the yield and risk changes of the hedge portfolio under the impact of the "false vaccine" event. This paper studies the influence of margin trading and short selling system on stock pricing efficiency through the return and risk of portfolio, which enriches the relevant research of margin and short margin system in China. On the other hand, referring to the definition of stock heterogeneity information by Liu Shancun (2018) in [8], this paper constructs the index (PSF) to measure pricing efficiency from the perspective of heterogeneous information content of stock price. The definition of stock heterogeneity information in this paper is different from the previous considerations, and it can be used as a reference for the later study on the dimension of heterogeneity information content in stock pricing efficiency.

\section{The Drive Event, Samples, and Hedge Portfolios}

\subsection{The Drive Event}

The "unqualified vaccine" event of Changsheng Life Biotechnology Co., Ltd. has had an important external impact on the biological vaccine industry, and there are both margin and non-margin stocks in the industry. The "false vaccine event" in this industry provides an ideal background for this paper to study the impact of margin financing on stock pricing efficiency.

On July 15, 2018, the State Drug Administration issued a circular that the State Drug Administration carries out an unannouncement inspection on the production field of Changsheng Life Biotechnology Co., Ltd. Inspection team 
found that Changsheng Life Biotechnology Co., Ltd. made false record in the production process of rabies vaccine (Verocell) for human use and had other serious violations of the Drug production quality Management Standard (GMP). According to the inspection results, the State Drug Administration ordered Food and Drug Administration in Jilin to take back the Drug GMP Certificate from Changsheng Life Biotechnology Co., Ltd., and requested Changsheng Life Biotechnology Co., Ltd. to stop all rabies vaccine production.

The "false vaccine event" has had an important impact on the stock prices of listed companies in the biological vaccine industry. After the news that the illegal production of rabies vaccine was filed and investigated, Changsheng Life Biotechnology Co., Ltd.'s share price fell to limit for 32 trading days in a row, and the biological vaccine industry suffered a severe setback. However, except for the fact that the culprit was most affected, the "unqualified vaccine incident" had different effects on the various listed companies in the biological vaccine industry. Miller (1977) in [1] thinks when investors have pessimistic expectations about the future return on stocks but there is no short selling mechanism in the market, the pessimistic investors are forced to leave the market because they are unable to short the stocks, and the negative information of the investors cannot be fully reflected in the stock price, which leads to the overvaluation of the stock price. In this paper, only some listed companies in the biological vaccine industry have approved the financing and short selling business, which can fully reflect the negative effects of the "unqualified vaccine event" while stocks that cannot be shorted do not sufficiently reflect the impact of negative information.

\subsection{Samples and Hedge Portfolios}

In this paper, the stock price data and financial data of the companies come from the CSMAR database. This paper selects the listed companies of the biological vaccine industry as the research samples. The sample range is from April 15, 2018 to October 15, 2018, covering all trading sessions. According to the Industry Classification of listed companies published by the China Securities Regulatory Commission, the biological vaccine industry contains twenty-two listed companies. These twenty-two listed companies are divided into two groups which are short selling group and non-short selling group, according to whether they are allowed to carry out margin financing and short selling business. According to the current listing of companies on the market, the biological vaccine industry includes stocks of twelve listed companies allowed to carry out margin trading and short selling business. They are Changchun High \& New Technology Industrials (Group) Inc., Chengdu Taihe Health Technology Group Inc., Ltd., Hualan Bio-Technology Group Inc., Ltd., Shuanglu Pharmaceutical Group Inc., Ltd., Tianjin Lisheng Pharmaceutical Group Inc., Ltd., Chongqing Zhifei Biological Products Co., Ltd., Fosun Pharmaceutical Group Inc., Ltd., Jinyu Bio-technology Co., Ltd., Guangzhou Baiyunshan Pharmaceutical Holdings Co., Ltd., Zhejiang Conba Pharmaceutical Co., Ltd., Liaoning Chengdu Co., Ltd., 
Shanghai Haixin Group Co., Ltd. And the other stocks of ten listed companies are currently not allowed to carry out margin trading and short selling business. They are Beijing Four Rings Biopharmaceutical Co., Ltd., Yueyang Xingchang Petrochemical Co., Ltd., Guangji Pharmaceutical Group Inc., Ltd., Sinobioway Group Co., Ltd., Changsheng Life Biotechnology Co., Ltd., Walvax Biotechnology Co., Ltd., Boya Bio-pharmaceutical Co., Ltd., Shenzhen Kangtai Biological Products Co., Ltd., Yabao Pharmaceutical Group Inc., Ltd., Huabei Pharmaceutical Group Inc., Ltd. These 10 stocks are defined as the non-short-selling group in this paper.

Based on the definitions above about short-selling group and non-short-selling group, four different hedge portfolios are constructed. The first type of portfolio (defined as Strategy A) is to buy 10 stocks in the non-short-selling group with the same weight, that is, to buy non-short groups, and to short selling 12 stocks that are allowed to short, that is, short selling groups. Considering that the "false vaccine event" is directed at Changsheng Life Biotechnology Co., Ltd., the event could have a significant impact on Changsheng Life Biotechnology Co., Ltd.'s stock price. In order to control this particular effect, this paper constructs a second portfolio (defined as the strategy of B), to buy nine stocks which cannot be short excluding Changsheng Life Biotechnology Co., Ltd. with the same weight, and to short the stocks of the group of short selling with equal weight at the same time. Considering that the market capitalization factor of the stock may cause asymmetric effects of the "false vaccine event" on different stocks, the third portfolio (defined as the strategy $\mathrm{C}$ ), is constructed in this paper excluding Fosun Pharmaceutical Group Inc., Ltd., the largest company by market capitalization in the biological vaccine industry, that is to buy 10 stocks that cannot be short by weight, and shorten the shares that can be sold short excluding Fosun Pharmaceutical Group Inc., Ltd. Finally, the fourth portfolio (defined as Strategy D) excludes both Changsheng Life Biotechnology Co., Ltd. and Fosun Pharmaceutical Group Inc., Ltd., and buys stocks that cannot be shorted after Changsheng Life Biotechnology Co., Ltd. is excluded in the same weight. At the same time short selling the same weight of the short-selling group by excluding Fosun Pharmaceutical Group Inc., Ltd.

\subsection{Returns on Hedge Portfolios}

The changes in returns of hedge portfolios A, B, C and D before and after the "false vaccine event" are shown in Figure 1.

As can be seen from Figure 1, before the "false vaccine event", the cumulative returns of the four hedging strategies fluctuated around zero, indicating that the stocks of both the short-selling and non-short-selling groups were influenced by the macroeconomy, the influence of industry and market risk factors. Through the establishment of hedge investment portfolio, investors can hedge this part of systemic risk, so the investment strategy is market neutral. In addition, after the "false vaccine event", the cumulative return rate of the four hedge investment 


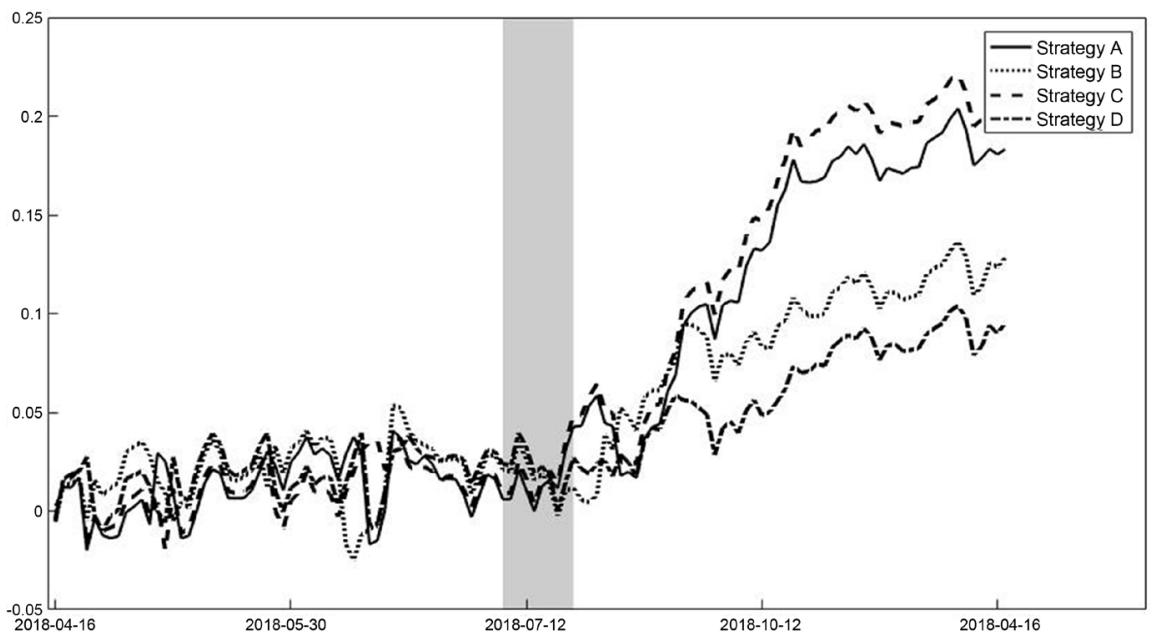

Figure 1. Return rates of hedge portfolio A, B, C, D ${ }^{1}$.

strategies continued to rise significantly, and the cumulative return rate of the portfolio reached $10 \%-20 \%$ three months after the "false vaccine event". The result shows that the "false vaccine event" has an important impact on the stock price of the listed companies in the biological vaccine industry in China, and the impact of the event on the stock price depends on whether the stock can be short sold. A hedge investment portfolio based on the biological vaccine industry in this paper can produce significant benefits after the "false vaccine event", which is similar to Li Ke, Xu Longbing and Zhu Weihua (2014) building hedge portfolios based on the liquor industry and producing positive return after the plasticizer event [9]. This paper argues that, as a major negative news for the industry, the "fake vaccine incident" has a more profound impact on stocks that can short, that is, stocks that can sell short will fall more sharply than those that cannot. By shorting a short group and buying a non-short group, significant gains can be made after a "false vaccine event" occurs.

\section{Empirical Study on Stock Pricing Efficiency of Margin Trading and Short Selling}

This paper argues that the reason why the four hedging strategies can gain significant profits after the "false vaccine event" is that the shares that cannot be short are overvalued because of the short selling restriction compared to the stocks that can be shorted. However, limited in the perspective of portfolio returns, it is clear that margin trading and short selling affects the pricing efficiency of stocks is not convincing enough, so this paper manage to measure the efficiency of stock pricing.

\subsection{Basic Model}

In order to test whether margin trading and short selling system has an impact on the pricing efficiency of stocks, referring to Li Zhisheng, Chen, Lin Bingxuan

${ }^{1}$ The shadow area represents the five trading days before and after the false vaccine event. The data source is CSMAR database. 
(2015) in [10], we select the cross-section data model in this paper. Through constructing the pricing efficiency index as the explained variable in the model and adding the dummy variable Short_List ${ }_{i}$ which represents the margin trading and short selling system as the explanatory variable, this paper studies the differences in pricing efficiency between margin trading and short selling group and non-margin-trading-and-short-selling group in the hedge portfolio of biological vaccine industry. The specific models are as follows:

$$
\text { Efficiency }_{i}=\alpha_{0}+\beta \times \text { Short_List }_{i}+\gamma \times \text { Controls }_{i}+\varepsilon_{i}
$$

where the explained variable Efficiency ${ }_{i}$ represents the pricing efficiency of the stock $i$ during the sample period, the explanatory variable Short_List ${ }_{i}$ is a dummy variable, when the stock $i$ is the subject of margin trading and short selling system during the sample period, the value is 1 , otherwise the value is zero. Controls ${ }_{i}$ denotes the control variable corresponding to the stock $i$, and $\varepsilon_{i}$ is a random perturbation term. If the regression coefficient of dummy variable Short_List ${ }_{i}$ is significantly positive, it shows that the pricing efficiency of stocks with margin trading and short selling is higher than that without it. If the regression coefficient of Short_List ${ }_{i}$ is significantly negative, the pricing efficiency of stock which is not allowed to sell short is higher than that of stock with margin trading. If the regression coefficient of Short_List ${ }_{i}$ is not significant, it shows that there is no significant difference in pricing efficiency between margin trading and short selling stocks and non-short-selling stocks, that is, margin trading will not have a significant impact on the pricing efficiency of stocks.

\subsection{Construction of Stock Pricing Efficiency Index}

This paper will investigate the pricing efficiency of stock from two angles: the information adequacy of stock price and the response timeliness of stock price information, and establish the index (PSF), the stock price idiosyncratic fluctuation and the lag of price response index (PLR), which is used to investigate the stock pricing efficiency respectively.

\subsubsection{The Index of Volatility of Stock Price (PSF)}

The heterogeneity information of stock refers to the information that affects the stock price except market information and industry information. Referring to Liu Shancun (2018)'s idea in [8], this article constructs the following models:

$$
r_{j, t}=\alpha_{j}+\beta_{j, 1} r_{m, t}+\beta_{j, 2} r_{m, t-1}+\beta_{j, 3} r_{i, t}+\beta_{j, 4} r_{i, t-1}+\varepsilon_{j, t}
$$

Among them, $r_{j, t}$ represents the stock return rate of the company $j$ at time $t$, $r_{m, t}$ represents the return rate of market index at time $t, r_{i, t}$ represents the industry return rate of the industry $i$ in time $t$, and $\varepsilon_{j, t}$ is a stochastic disturbance. By the regression of the model above, the residual term $e_{j, t}$ is obtained. The residual term $e_{j, t}$ can reflect the heterogeneity information of the company $j$. In this paper, the standard deviation of the residual term $e_{j, t}$ is defined as volatility of stock price which is PSF, that is, for a company $j$, the index of volatility of stock price is $\mathrm{PSF}_{j}$. The greater value of the index, the larger the fluctu- 
ation range of the content of the stock price contains the heterogeneity information, which means the less sufficient the stock price containing all kinds of information, and the lower the pricing efficiency is.

\subsubsection{The Index of Price Response Lag (PLR)}

This paper refers to the adjustment speed of asset price to market information proposed by Saffi and Sigurdsson in [11], Boehmer and $\mathrm{Wu}$ in [12] to measure the speed of stock price absorbing new market information and constructs the index of price lag reaction. If the market can not reflect the information to the stock price in time, the information will be absorbed by the individual stock in the following time, forming the price lag reaction. Therefore, the lag of price response can be obtained by the regression model of market yield with lag. The stronger the explanatory power of lag variable, the slower the reaction speed of stock price to market information, the lower the pricing efficiency of individual stock. The specific regression models are as follows:

$$
r_{j, t}=\alpha_{j}+\beta_{j} \times r_{m, t}+\sum_{n=1}^{4} \delta_{j, n} \times r_{m, t-n}+\varepsilon_{j, t}
$$

where $r_{j, t}$ represents the stock return rate of the company $j$ at time $t, r_{m, t}$ represents the return rate of market index at time $t, r_{m, t-n}$ represents the yield of the market index with lag $n$. By regression to the model above, the determinable coefficient $R^{2}$ of regression is obtained, and then, by constraining the coefficient of return of all lagging markets is 0 , the determinable coefficient $R^{\prime 2}$ of constraint regression is obtained.

Therefore, the first price lag response index can be constructed:

$$
\mathrm{PLR}_{1, j}=1-\frac{R^{\prime 2}}{R^{2}}
$$

$\mathrm{PLR}_{1, j}$ captures the ratio of return on a single asset explained by the lagging market rate of return. The smaller the $\mathrm{PLR}_{1, j}$ value, the less dependent the rate of return on the past market information, which also means the faster the asset absorbs market information, the higher the pricing efficiency. In addition to the determinable coefficient of regression equation, this paper also uses the coefficient size of the explanatory variable in the regression equation to measure the dependence of the return rate on the lagging market rate of return, and thus obtains the second lag response index:

$$
\operatorname{PLR}_{2, j}=\frac{\sum_{n=1}^{4}\left|\delta_{j, n}\right|}{\left|\beta_{j}\right|+\sum_{n=1}^{4}\left|\delta_{j, n}\right|}
$$

$\mathrm{PLR}_{2, j}$ captures the proportion of the return coefficient of the lagging market in Equation (2) in all regression coefficients. The smaller the value is, the higher the pricing efficiency of the stock is.

\subsection{Selection of Control Variables}

\subsubsection{Stock Exchange (Exchange)}

There are two stock exchanges in China, namely Shanghai Stock Exchange and 
Shenzhen Stock Exchange. Although the stocks in the two exchanges face the same economic and market environment and are subject to the same supervision, there are some differences between the two exchanges in terms of the issuance system, the information disclosure system, the composition of investors, etc. This paper believes that these factors may have a systematic impact on the pricing of stocks. We define the exchange dummy variable of individual stock i as Exchange ${ }_{i}$. When the stock comes from the Shanghai Stock Exchange, the value is 1 , and when the stock comes from the Shenzhen Stock Exchange, the value is 0 .

\subsubsection{Book to Market (B/M)}

Fama and French (1993) found that the ratio of book to market value is the key factor to affect the stock price, which will have an important impact on the pricing efficiency of the stock [13]. In order to control the interference of this factor, the average book-to-market ratio of each stock during the sample period is included in the control variable category.

\subsubsection{Turnover}

According to Sadka and Scherbina (2007) in [14] and Chordia, T., R, Roll, Subrahmanyam (2008) in [15], there is a significant correlation between stock liquidity and pricing efficiency. The lower liquidity of stocks represents higher transaction costs, which will hinder informed traders from trading, resulting in information not being transmitted to the stock price in a timely and complete manner. On the contrary, in an adequate liquidity market, informed traders are more motivated to trade through the information obtained, thus improving the pricing efficiency of stocks. Based on this, in the regression analysis, the stock turnover rate is controlled, and the average turnover rate of each stock during the sample period is added as the control variable.

\subsubsection{The Percentage of Broker Holding Stocks in the Recent Quarter (Broker)}

Considering that investors involved in margin trading and short selling need to borrow funds or securities from securities brokers as the supply side of funds or securities and investors as the demand side, whether there is a conflict of interest between the two party may also affect the effect of margin trading and short selling on stock pricing efficiency. For example, when investors need to borrow stocks and sell short, if the stock is a component of the broker's proprietary portfolio, the broker does not want investors to sell too much short securities; Instead, when investors want to buy stocks that are a component of a broker's proprietary portfolio, broker are willing to make it easier for investors to finance trading. Based on this, this paper takes the percentage of broker holding stock in the last quarter of the sample period as the control variable of the model.

\section{Data Description}

We choose the CSI 300 Index as the market index. Based on the stock data of 
CSI 300 Index and the biological vaccine industry from April 15, 2018 to October 15,2018 , the descriptive statistics of the main variables are calculated in $\mathrm{Ta}$ ble 1 .

As we can be seen from Table 1 Panel A, the three pricing efficiency indexes psf, $p l r_{1}, p l r_{2}$ constructed in this paper show great volatility, and the coefficient of variation is $29.91 \%, 76.19 \%$ and $31.47 \%$, respectively. There are significant differences in pricing efficiency among different stocks representing the biological vaccine industry in China. In addition, Table 1 Panel B calculates the correlation coefficient matrix between the three pricing efficiency indicators. Table 1 Panel B shows that the correlation coefficients between psf and $p l r_{1}$, $p l r_{2}$ are 0.2614 and 0.2578 , respectively, but the correlation coefficients are not significant at the $5 \%$ level, indicating that there is no significant correlation between these two pricing efficiency indicators. Psf captures the volatility of the heterogenous information content in the stock price, and measures the adequacy of the information content in the stock price. $p l r_{1}$ and $p l r_{2}$ captures the speed at which stock prices absorb new market information and measures the timeliness of stock price responses to information. Because the two price lag response indexes $p l r_{1}$ and $p l r_{2}$ are approximately the same at the construction method, they have a high and highly significant correlation. At the same time, these two indexes complement each other in measuring the timeliness of stock price response to information. plr measures the proportion of $R^{2}$ in the regression model explained by the lagging market index rate of return. $\mathrm{plr}_{2}$ describes the relative size of the return coefficient of the market index in the regression model. They measure the timeliness of the information reflected by the stock price from different angles.

Table 1. Descriptive statistical analysis of pricing efficiency indicators. (a) Panel A: Descriptive statistics of major variables; (b) Panel B: Correlation coefficient between pricing efficiency indicators.

(a)

\begin{tabular}{cccccc}
\hline Variable & Mean & Std. Dev. & Coef. Var & Min & Max \\
\hline$p s f$ & 0.0214 & 0.0064 & 0.2991 & 0.0117 & 0.0335 \\
$p l r_{1}$ & 0.1281 & 0.0976 & 0.7619 & 0.0167 & 0.3372 \\
$p l r_{2}$ & 0.3759 & 0.1183 & 0.3147 & 0.1883 & 0.5811 \\
\hline
\end{tabular}

(b)

\begin{tabular}{cccc}
\hline Variable & $p s f$ & $p l r_{1}$ & $p l r_{2}$ \\
\hline$p s f$ & 1.0000 & 0.2614 & 0.2578 \\
& & $(0.2400)$ & $(0.2467)$ \\
$p l r_{1}$ & 0.2614 & 1.0000 & 0.9548 \\
& $(0.2400)$ & & $(0.0000)$ \\
$p l r_{2}$ & 0.2578 & 0.9548 & 1.0000 \\
\hline
\end{tabular}

Note: The number of brackets in Panel B represents the $\mathrm{p}$ value corresponding to the significance test of the correlation coefficient. The data comes from CSMAR database. 
Table 2. Analysis of pricing efficiency difference between margin trading and short selling stock and non-margin-trading-and-short-selling stock.

\begin{tabular}{|c|c|c|c|}
\hline Variable & $p s f$ & $p l r_{1}$ & $p l r_{2}$ \\
\hline \multirow{3}{*}{ Intercept } & 1.606 & 0.144 & 0.435 \\
\hline & $(0.201)$ & $(0.031)$ & $(0.036)$ \\
\hline & {$[0.000]$} & {$[0.000]$} & {$[0.000]$} \\
\hline \multirow{3}{*}{ Short_List } & -0.282 & -0.070 & -0.095 \\
\hline & $(0.123)$ & $(0.026)$ & $(0.033)$ \\
\hline & {$[0.036]$} & {$[0.016]$} & {$[0.011]$} \\
\hline \multirow{3}{*}{ Exchange } & -0.037 & -0.096 & -0.114 \\
\hline & $(0.180)$ & $(0.021)$ & $(0.028)$ \\
\hline & {$[0.842]$} & {$[0.000]$} & {$[0.001]$} \\
\hline \multirow{3}{*}{$\mathrm{B} / \mathrm{M}$} & -0.432 & -0.068 & -0.087 \\
\hline & $(0.314)$ & $(0.052)$ & $(0.065)$ \\
\hline & {$[0.188]$} & {$[0.214]$} & {$[0.200]$} \\
\hline \multirow{3}{*}{ Turnover } & 0.415 & 1.272 & 0.701 \\
\hline & $(0.048)$ & $(1.327)$ & (1.787) \\
\hline & {$[0.000]$} & {$[0.352]$} & {$[0.700]$} \\
\hline \multirow{3}{*}{ Broker } & 0.028 & 0.743 & 0.665 \\
\hline & $(0.010)$ & $(0.134)$ & $(0.214)$ \\
\hline & {$[0.012]$} & {$[0.000]$} & {$[0.007]$} \\
\hline R-Square & 0.832 & 0.732 & 0.684 \\
\hline
\end{tabular}

Note: The numbers in parentheses represent heteroscedasticity autocorrelation robust standard errors (HAC) and the numbers in square brackets represent the $\mathrm{p}$ values corresponding to the significance test of the estimation coefficients. The data source is CSMAR database.

\section{Empirical Results}

Based on the background that the four hedge investment strategies on the biological vaccine industry constructed in this paper can make significant profits after the "false vaccine event", this paper attempts to construct a pricing efficiency index from two angles: the adequacy of stock price information content and the timeliness of stock price response to information. This paper studies whether there is a significant difference in pricing efficiency between margin trading and short selling system and non-margin-trading-and-short-selling system in a basket of stocks in the biological vaccine industry. In this paper, the regression model (1) is estimated, and the corresponding regression results are shown in Table 2.

From Table 2, it can be found that the proxy variable of margin trading and short selling system, Short_List, has regression coefficients of $-0.282,-0.070$ and -0.095 for $p s f, p l r_{1}, p l r_{2}$ respectively. And the three regression coefficients are significantly different from zero at the level of 5\%, representing that in both the adequacy of the information content of the stock price and the timeliness of 
the response of the stock price to the information, the pricing efficiency of stocks which are allowed to margin trading and short selling business is significantly higher than that of non-margin-trading-and-short-selling business stocks.

About adequacy of information on stock prices, in addition to the proxy variable of margin trading and short selling system, Short_List, has a significant impact on the index of volatility of stock price ( $p s f)$, the paper finds that the turnover rate (Turnover) and the percentage of broker holding stocks in the recent quarter (Broker) are also important factors affecting psf. Specifically, the lower the stock turnover rate is and the lower the stockholding ratio is, the smaller the specific volatility index of the stock price is and the more sufficient the information content in the stock price is, thus the higher the pricing efficiency is. These findings are consistent with those of Li Zhisheng, Du Shuang, Lin Bingxuan (2015) in [16] and Fang Libing, Xiao Binqing (2015) in [17]. In addition, it is found that the stock exchange (Exchange) and book to market (B/M) have no significant effect on the adequacy of information content in the stock price.

About the timeliness of the stock price response to information, in addition to the proxy variable Short_List of margin trading and short selling system which has significant influence on the index of price lag response $p l r_{1} \& p l r_{2}$, this paper finds that the stock exchange (Exchange) which the stock is located in and the percentage of broker holding stocks in the recent quarter (Broker) are also important factors affecting $p l r_{1}$ and $p l r_{2}$. Specifically, stocks in Shanghai Stock Exchange whose stock price response to information is significantly higher than those in Shenzhen Stock Exchange. In addition, the lower the percentage of broker holding stocks in the recent quarter, the higher the timeliness of stock price response to information and the higher the pricing efficiency, which is consistent with the adequacy effect of Broker on the information content of stock price. In addition, it can be seen from Table 2 that the book-to-market value of individual stocks and the turnover rate have no significant effect on the pricing efficiency of individual stocks in the dimension of the timeliness of stock price response to information.

\section{Conclusions}

In this paper, twenty-two stocks in the biological vaccine industry in China are taken as the samples. Through simulating the return of hedge portfolios and constructing the pricing efficiency index, we study the effect of margin trading and short selling on the pricing efficiency of stocks in China. We found that firstly, using the "false vaccine event" happening in Changsheng Life Biotechnology Co., Ltd. as the driving event, we constructed hedge portfolios based on the strategy of A, B, C and D and found that all portfolios have significant returns after the event; Secondly, we established the pricing efficiency indexes $p s f$, $p l r_{1}$ and $p l r_{2}$ from the adequacy of stock price information and the timeliness of stock price response to information. It is found that the pricing efficiency of the stocks which are allowed to margin trading and short selling business is sig- 
nificantly higher than that of stocks which are not allowed to sell short. This result may explain why the hedge portfolios we construct have positive return. The "false vaccine incident" has a more far-reaching impact on the stocks that can be shorted. The stock that is allowed to sell short can reflect the negative information more fully; its fall range will be bigger than that cannot be sold short.

The result in this paper provides evidence from developing countries for the conclusion that margin trading and short selling system is conducive to improving the pricing efficiency of individual stocks and improving the quality of the stock market. We believe that China's regulators should take further measures to reduce the barriers and transaction costs of margin trading, and gradually expand the number of stocks that are allowed to sell short in order to promote the healthy development of our stock market.

\section{Conflicts of Interest}

The author declares no conflicts of interest regarding the publication of this paper.

\section{References}

[1] Miller, E.M. (1997) Risk, Uncertainty, and Divergence of Opinion. Journal of Finance, 32, 1151-1168. https://doi.org/10.1111/j.1540-6261.1977.tb03317.x

[2] Duffie, D., Garleanu, N. and Pedersen, L.H. (2002) Securities Lending, Shorting, and Pricing. Journal of Financial Economics, 66, 307-339. https://doi.org/10.1016/S0304-405X(02)00226-X

[3] Aitken, M.J., Frino, A., Mccorry, M.S. and Swan, P.L. (1998) Short Sales Are Almost Instantaneously Bad News: Evidence from the Australian Stock Exchange. Journal of Finance, 53, 2205-2223. https://doi.org/10.1111/0022-1082.00088

[4] Danielsen, B.R. and Sorescu, S.M. (2001) Why Do Option Introductions Depress Stock Prices? A Study of Diminishing Short Sale Constraints. Journal of Financial and Quantitative Analysis, 36, 451-484. https://doi.org/10.2307/2676220

[5] Allen, F. and Gale, D. (1991) Arbitrage, Short Sales, and Financial Innovation. Econometrics, 59, 1041-1068. https://doi.org/10.2307/2938173

[6] Huang, F.M. (2018) A Study on the Stock Price Effect of the Adjustment of the Stocks in Margin Trade and Short Selling System-A Shares in Shenzhen Stock Market as an Example. Contemporary Finance and Economics, No. 4, 45-53.

[7] Brunnermeier, M.K. and Pedersen, L.H. (2005) Predatory Trading. Journal of Finance, 60, 1825-1863. https://doi.org/10.1111/j.1540-6261.2005.00781.x

[8] Liu, S.C., Cheng, B.H., Yang, Z. and Liu, J.Y. (2018) Research on the Influence of Margin Trade and Short Selling on the Volatility of Stock Price. Journal of Beijing Jiaotong University (Social Sciences Edition), 17, 61-70.

[9] Li, K., Xu, L.B. and Zhu, W.H. (2014) Short Selling Restriction and Stock Mispricing: Evidence of Margin Trade and Short Selling. Economic Studies, No. 10, 165-178.

[10] Li, Z.S., Chen, C. and Lin, B.X. (2015) Does Short Selling Improve Pricing Efficiency in China's Stock Market?-Evidence Based on Natural Experiments. Economic Studies, 50, 165-177.

[11] Saffi, P.A. and Sigurdsson, K. (2011) Price Efficiency and Short-Selling. Review of 
Financial Studies, 24, 821-852. https://doi.org/10.1093/rfs/hhq124

[12] Boehmer, E. and Wu, J. (2013) Short Selling and the Price Discovery Process. Review of Financial Studies, 26, 287-322. https://doi.org/10.1093/rfs/hhs097

[13] Fama, E.F. and French, K.R. (1993) Common Risk Factors in the Returns of Stocks and Bonds. Journal of Financial Economics, 33, 3-56. https://doi.org/10.1016/0304-405X(93)90023-5

[14] Sadka, R. and Scherbina, A. (2007) Analyst Disagreement, Mispricing and Liquidity, Journal of Finance, 62, 2367-2403. https://doi.org/10.1111/j.1540-6261.2007.01278.x

[15] Chordia, T., Roll, R. and Subrahmanyam, A. (2008) Liquidity and Market Efficiency. Journal of Financial Economics, 87, 249-268. https://doi.org/10.1016/j.jfineco.2007.03.005

[16] Li, Z.S., Du, S. and Lin, B.X. (2015) Short Selling and Stock Price Stability: a Natural Experiment from China's Margin Trade and Short Selling Market. Financial Studies, No. 6, 1873-1888.

[17] Fang, L.B. and Xiao, B.Q. (2015) The Influence of Margin Trade and Short Selling System Imbalance on the Pricing Efficiency of Stocks. Contemporary Economic Science, 37, 48-56, 125-126. 